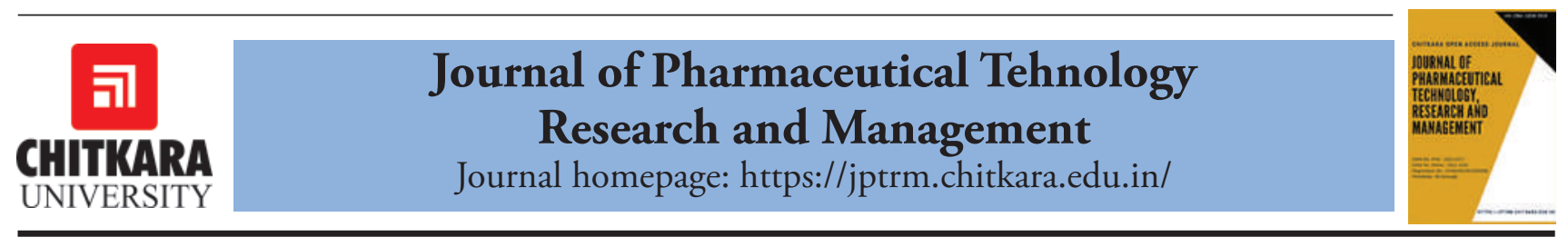

\title{
Molecular Docking Studies of Phenolic Compounds from Syzygium cumini with Multiple Targets of Type 2 Diabetes
}

\author{
Ajmer Singh Grewal, Neelam Sharma, Sukhbir Singh and Sandeep Arora* \\ Chitkara College of Pharmacy, Chitkara University, Rajpura, Patiala, 140401, Punjab, India
}

*Email: sandeep.arora@chitkara.edu.in

\section{ARTICLE INFORMATION}

Received: June 17, 2018

Revised: Aug. 28, 2018

Accepted: Oct. 27, 2018

Published online: Nov. 2, 2018

Keywords:

Alpha-glucosidase, Dipeptidyl peptidase 4, Glucagon receptor, Glucokinase, Glycogen synthase kinase 3, Phenolic compounds, Syzygium cumini.

\author{
ABSTRACT
}

Treatment of type 2 diabetes without any side effects is still a challenge to the medical system. This leads to increasing demand for natural products with antidiabetic activity with fewer side effects. Syzygium cumini is a traditional herbal medicinal plant and is reported to possess a variety of pharmacological actions. It contains various types of chemical constituents including terpenoids, tannins, anthocyanins, flavonoids and other phenolic compounds. Some flavonoids and other phenolic compounds from $S$. cumini were reported in literature to have type 2 antidiabetic potential. The main objective of the current investigation was in silico screening of some phenolic compounds from $S$. cumini against multiple targets associated with type 2 diabetes to explore the mechanism of antidiabetic action and prediction of binding mode using molecular docking studies. In silico docking studies were performed for the selected molecules in the binding site of multiple targets associated with type 2 diabetes ( $\alpha$-glucosidase, dipeptidyl peptidase 4 , glycogen synthase kinase 3 , glucokinase and glucagon receptor). Amongst the compounds tested in silico, rutin showed appreciable binding with multiple targets of type 2 diabetes including $\alpha$-glucosidase, dipeptidyl peptidase 4 , glycogen synthase kinase 3 , and glucagon receptor. Catechin was found to inhibit both $\alpha$-glucosidase, and dipeptidyl peptidase 4 . This information can be utilized for the design and development of potent multi-functional candidate drugs with minimal side effects for type 2 diabetes therapeutics. and side effects. This caused the scientific community to search for new antidiabetic drugs (Olokoba et al., 2012; Osadebe et al., 2014). Large numbers of plants and parts of plants were reported with their antidiabetic properties. Various types of plant-derived active principles representing several bioactive compounds have established their beneficial role for possible use in T2D therapeutics (Patil et al., 2011; Ibrahim et al., 2013; Kumar et al., 2012). Syzygium cumini (Linn.) is an economically important tropical fruit tree belonging to the family Myrtaceae largely grown in Indian subcontinent along with some other parts of South Asia including Bangladesh, Sri Lanka, Nepal, Pakistan, Burma and Indonesia. It is also cultivated in some parts of Africa and South America (Swami et al., 2012; Srivastava and Chandra, 2013). It is commonly known as jamun in India, black plum in Europe, jambolan in Spanish spoken countries, and Jambolac in Brazil. It is also known as java plum, Indian blackberry, Portuguese plum, Malabar plum, purple plum, Jamaica and damson plum (Ayyanar and Subash-Babu, 2012; Chagas et al., 2015). Various types of secondary metabolites like flavonoids (quercetin, rutin, catechin, kaempferol, myricetin, isoquercetin, could lead to severe hypoglycemia resulting in brutal toxic 
myricetin deoxyhexoside, myricetin-3-L-arabinoside, dihydromyricetin, quercetin-3-D-galactoside, myricetin 3-O- $\beta$-D-glucuronopyranoside, myricetin-4'-methylether 3-O- $\alpha$-rhamnopyranoside), phenolic acids (caffeic acid, chlorogenic acid, ellagic acid, Ferulic acid, gallic acid, 3,3'-di-O-methyl ellagic acid,3,3',4-tri-O-methyl ellagic acid), tannins (nilocetin Corilagin, 3,6-HHDP glucose, 4,6-HHDP glucose, 1-galloyl glucose, 3-galloyl glucose, HHDP-galloyl glucose, trigalloyl glucose, Eugenol, and oleanolic acid), terpenes ( $\alpha$-pinene, $\alpha$-cadinol, pinocarvone, pinocarveol, $\alpha$-terpeneol, myrtenol, eucarvone, muurolol, myrtenal, cineole, geranyl acetone, $\beta$-pinene, $\beta$-terpinene, betulinic acid, eugenol, citronellol, geraniol, hotrienol, nerol, $\beta$-phenylethanol, phenylpropanal, $\beta$-siterol, and friedelin), anthocyanins (Cyanidin, delfinidin and petudinin), alkaloids (jambosine), glycosides (jamboline and antimelin), minerals $(\mathrm{Ca}, \mathrm{Mg}, \mathrm{Na}, \mathrm{K}$, and $\mathrm{Cu}$ ), vitamins (thiamine, riboflavin, and nicotinic acid) are present in different parts of the plant (Veigas et al., 2007; Ramya et al., 2012; Ayyanar and Subash-Babu, 2012; Chagas et al., 2015; Bijauliya et al., 2017). S. cumini is known to possess wide range of pharmacological and therapeutic properties, which have been attributed to the presence of bioactive compounds in different parts of the plant (Srivastava and Chandra, 2013). A variety of various pharmacological activities were shown by S. cumini including anti-diabetic (Kumar et al., 2008, Tripathi and Kohli, 2014), anti-cancer (Afify et al., 2011), anti-oxidant (Nair et al., 2013), antibacterial/antimicrobial (Prateek et al., 2015), anti-inflammatory (Muruganandan et al., 2001), anti-diarrhoeal (Shamkuwar et al., 2012), antiviral (Sood et al., 2012), cardio-protective (Herculano et al., 2014), anticonvulsant (Kumar et al., 2007), antinociceptive
(Avila-Pena et al., 2007), gastro-protective (Chaturvedi et al., 2009), anti-fertility (Rajasekaran et al., 1998), chemoprotective (Goyal et al., 2010), anti-allergic (Brito et al., 2007), inhibition of lipid peroxidation (Veigas et al., 2007), anti-histaminic (Mahapatra et al., 1986), anti-pyretic (Mahapatra et al., 1986), anti-plaque (Namba et al., 1985), anti-hyperlipidemic (Chagas et al., 2015) and hepatoprotective activity (Veigas et al., 2008). Some flavonoids and other phenolic derivatives obtained from S. cumini including quercetin, myricetin, kaempferol, ferulic acid, ellagic acid, catechin and rutin were reported in literature to have type 2 antidiabetic potential (Haraguchi et al., 1998; Ohnishi et al., 2004; Kamalakkannan and Prince, 2006; Liu et al., 2007; Sharma et al., 2008; Esmaeili et al., 2009; Wein et al., 2010; Bardy et al., 2013; Chagas et al., 2015). Currently, medicinal chemistry research is focussed on polypharmacological compounds acting on multiple targets against complex disorders including diabetes, neoplastic diseases, neurodegenerative disorders, and certain infectious disorders owing to superior efficacy, better safety profile, and ease of administration of multi-target drugs. Molecular docking is one of the most widely used techniques for the design of multi-target drugs (EspinozaFonseca, 2006; Scotti et al., 2017; Ramsay et al., 2018). In the current investigation docking studies were performed for some phenolic compounds obtained from S. cumini (Figure 1) in the binding site of multiple targets associated with T2D ( $\alpha$-glucosidase (AG), dipeptidyl peptidase 4 (DPP4), glycogen synthase kinase 3 (GSK3), glucokinase (GK) and glucagon receptor (GCR)) in order to explore the mechanism of antidiabetic action and binding modes using molecular docking studies.<smiles></smiles>

Figure 1: Phenolic compounds from Syzygium cumini with potential antidiabetic activity selected for in silico studies. 


\section{Experimental}

\subsection{In Silico Prediction of Pharmacokinetic Parameters}

All the selected molecules were analyzed for prediction of pharmacokinetic parameters related to absorption, distribution, metabolism, and excretion (ADME) by employing FAFDrugs 4 server; and evaluated using Lipinski's rule of five for drug-likeness (Miteva et al., 2006; Lagorce et al., 2017).

\subsection{Molecular Docking Studies}

In silico molecular docking studies were carried out for the selected molecules in the binding site of target proteins using AutoDock Vina (Trott and Olson, 2010) and AutoDock Tools (Morris et al., 2009). The 2-D chemical structures of all the compounds were prepared by MarvinSketch (Marvin 15.9.21, 2015, ChemAxon) and 3-D conformations were generated using Frog2 server (Miteva et al., 2010). The ligands were converted to "pdbqt" files from "mol" format using AutoDock Tools. After assessing a numbers of cocrystallized structures for target proteins available in the protein data bank (https://www.rcsb.org); the best ligand bound complexes (PDB entries: 3L4T, 4A5S, 1Q5K, 3IMX and 5EE7 for AG, DPP4, GSK3, GK and GCR, respectively) were selected with complexes having maximum resolution and best binding interactions between ligands and proteins. An analogous docking method was used for the molecular docking of the selected derivatives as described in detail in earlier publications using AutoDock Vina and the ligand poses with most favorable docking score (binding free energy) were selected (Grewal et al., 2017; Charaya et al., 2018). The binding interactions of the ligands with the target proteins were analysed further for the docked poses of the ligands using PyMOL (The PyMOL Molecular Graphics System, Version 0.99rc6, Schrödinger, LLC).

\section{Results and Discussion}

\subsection{Pharmacokinetic Parameters}

ADME properties including molecular weight (MW), partition coefficient $(\log \mathrm{P})$, topological polar surface area (tPSA), water solubility $\left(\log S_{w}\right)$, hydrogen bond acceptors (HBA), hydrogen bond donors (HBD), solubility (mg/ $\mathrm{mL}$ ) and number of rotatable bonds were predicted for all the molecules selected for docking studies. Almost all the compounds showed good pharmacokinetic parameters and drug-like properties as contrived by Lipinski's rule of five (Table 1).

Table 1: Predicted pharmacokinetic parameters (ADME properties) of the compounds selected for docking studies.

\begin{tabular}{lcccccccc}
\hline Compound & MW $^{*}$ & $\log \mathbf{P}^{*}$ & tPSA $^{*}$ & $\log \mathbf{S}_{\mathrm{w}}{ }^{*}$ & HBA $^{*}$ & HBD $^{*}$ & Solubility & Rotatable bonds \\
\hline Quercetin & 302.24 & 1.54 & 131.03 & -2.99 & 7 & 5 & 15.23 & 1 \\
Myricetin & 318.24 & 1.18 & 151.26 & -2.85 & 8 & 6 & 18.42 & 1 \\
Kaempferol & 286.24 & 1.90 & 110.18 & -3.13 & 6 & 4 & 12.54 & 1 \\
Ferulic acid & 194.18 & 1.51 & 69.59 & -1.98 & 4 & 2 & 26.75 & 3 \\
Catechin & 290.27 & 0.51 & 110.38 & -2.15 & 6 & 5 & 33.86 & 1 \\
Ellagic acid & 302.19 & 1.10 & 140.68 & -2.83 & 8 & 4 & 17.84 & 0 \\
Rutin & 606.57 & 0.08 & 250.64 & -3.41 & 14 & 10 & 20.06 & 6 \\
\hline
\end{tabular}

\subsection{Molecular Docking Study}

The docking simulations were carried out by energy minimization and optimization of selected ligands in the binding site of target protein (PDB entries: 3L4T, 4A5S, 1Q5K, 3IMX and 5EE7 for AG, DPP4, GSK3, GK and GCR, respectively). The reference ligands was docked into the active site of target proteins; and the docked reference ligands produced a similar binding pattern and superposition on the binding mode of co-crystallized ligand validating accuracy of docking methodology. The docking score (binding free energy, $\Delta \mathrm{G}, \mathrm{kcal} / \mathrm{mol}$ ) of the selected compounds with various target proteins are presented in Table 2. Amongst the compounds tested in silico, myricetin, catechin and rutin showed appreciable binding interactions with AG; quercetin, catechin and rutin with DPP4; rutin with GCR, kaempferol with GK; and ferulic acid and rutin with GSK3 as determined by analysing the binding interactions of the selected best docked poses and $\Delta \mathrm{G}$ of the best docked poses. The docking studies of these molecules suggested a complimentary fit in the binding site of the target proteins. For the rest of the molecules, the molecules had a different orientation and binding pattern (flipping) in the binding site of the target protein possibly due to steric clashes of the substituents. Best docked compounds were further analyzed in details using PyMOL. 
Table 2: Docking score of the selected molecules for docking in the binding site of AG, DPP4, GSK3, GK and GCR proteins.

\begin{tabular}{lccccc}
\hline \multirow{2}{*}{ Ligand } & \multicolumn{5}{c}{ Docking score $(\Delta \mathbf{G}, \mathbf{k c a l} / \mathbf{m o l})$} \\
\cline { 2 - 6 } & AG & DPP4 & GCR & GK & GSK3 \\
\hline Quercetin & -6.7 & -8.2 & -6.5 & -7.2 & -6.9 \\
Myricetin & -7.4 & -8.1 & -6.7 & -6.5 & -7.2 \\
Kaempferol & -6.8 & -8.0 & -6.7 & -8.1 & -7.0 \\
Ferulic acid & -5.0 & -5.5 & -5.5 & -5.7 & -7.3 \\
Catechin & -7.2 & -7.3 & -6.7 & -6.8 & -6.8 \\
Ellagic acid & -6.5 & -9.3 & -7.3 & -7.8 & -6.4 \\
Rutin & -8.4 & -8.5 & -7.3 & -9.7 & -7.5 \\
Reference & -7.2 & & & -7.6 \\
\hline
\end{tabular}

Overlay of the docked poses of myricetin, catechin and rutin with that of PDB Ligand 3L4T in the binding site of AG showed that these molecules had the similar binding and orientation pattern in the binding site of enzyme as that of co-crystallized ligand (BJ2661 i.e., (1R,2S)-1-[(1S)-1,2-dihydroxyethyl]-3-[(2R,3S,4S)-3,4dihydroxy-2-(hydroxymethyl)tetrahydrothiophenium-1yl]-2-hydroxypropyl sulfate) (Figure 2a). The docked pose of myricetin in binding site of AG showed the H-bond interactions between carbonyl of chromen-4-one and $\mathrm{OH}$ of Asp203; 3-OH of chromen-4-one and $\mathrm{NH}_{2}$ of $\mathrm{Arg} 526$; $3-\mathrm{OH}$ of chromen-4-one and carbonyl of Asp542; $\mathrm{OH}$ of phenyl and carbonyl of Asp 327; and $\mathrm{OH}$ of phenyl and 'N' of His 600 with H-bond distance of $3.3 \AA$, $3.3 \AA$, 3.5
$\AA$ A, $2.8 \AA$, and $3.9 \AA$ respectively (Figure $2 \mathrm{~b}$ ). The docked pose of catechin in binding site of AG showed the H-bond interactions between hydroxyl of chromene and $\mathrm{NH}$ of Arg526; hydroxyl of chromene and carbonyl of Asp542; OH of phenyl and carbonyl of Asp327; and $\mathrm{OH}$ of phenyl and ' $\mathrm{N}$ ' of His 600 with H-bond distance of $3.2 \AA$, $3.0 \AA$, 2.9 $\AA$, and $4.4 \AA$ respectively (Figure 2c). The docked pose of rutin in binding site of $A G$ showed the $\mathrm{H}$-bond interactions between hydroxyl of glucose and 'N' of Arg526; hydroxyl of rhamnose and carbonyl of Asp203; ether ' $\mathrm{O}$ ' and hydroxyl of Asp542; hydroxyl of rhamnose and carbonyl of Asp327; and $\mathrm{OH}$ of glucose and ' $\mathrm{N}$ ' of His600 with $\mathrm{H}$-bond distance of $2.8 \AA$, $3.3 \AA$, $3.3 \AA$, $2.7 \AA$, and $3.3 \AA$ respectively (Figure 2d).
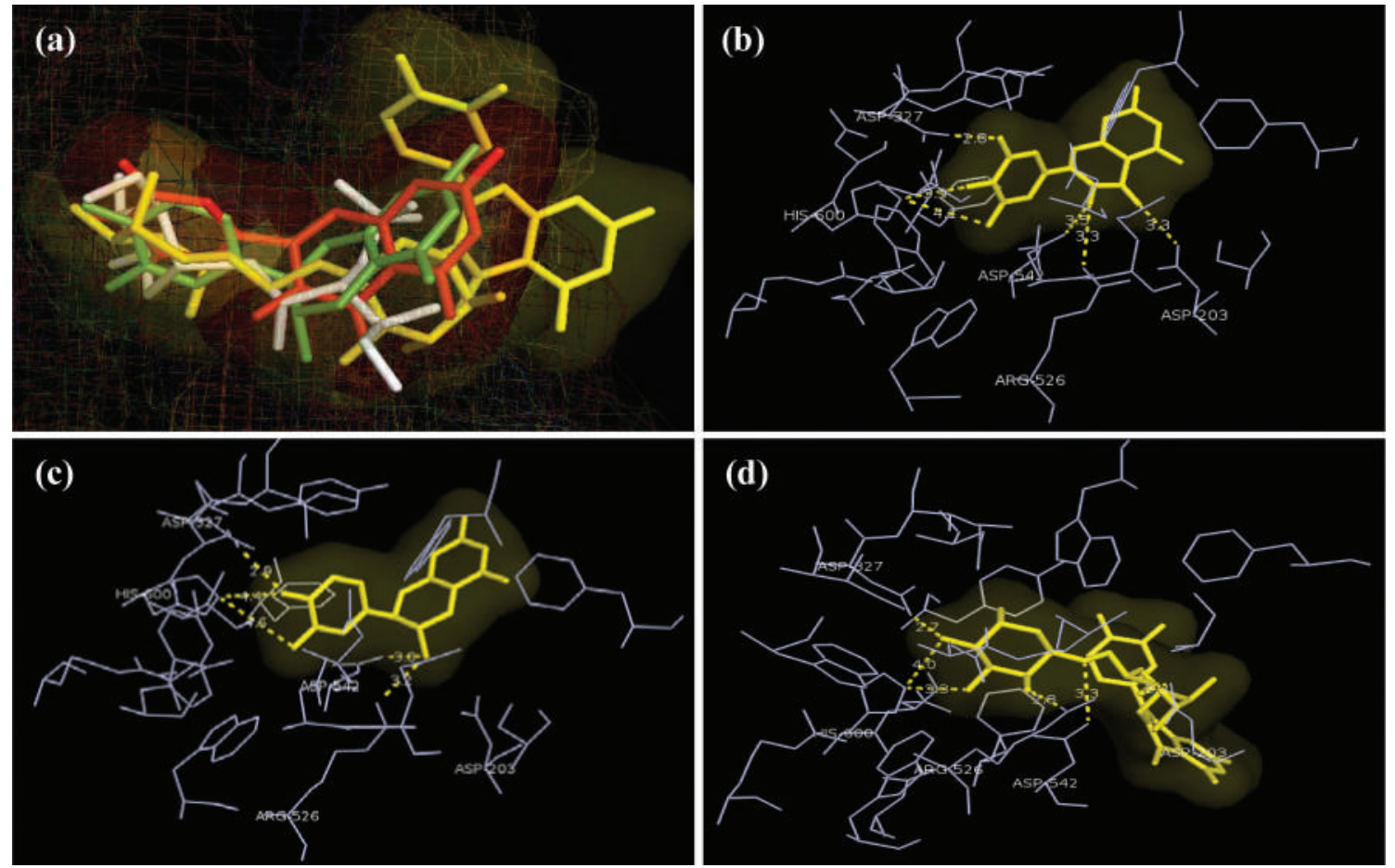

Figure 2: (a) Superimpose of myricetin (red), catechin (green) and rutin (yellow) with PDB ligand of 3L4T (white) in the binding site of AG; (b) Docked pose of myricetin; (c) catechin; (d) rutin in the binding site of AG. 
Overlay of the docked poses of quercetin, catechin and rutin with that of PDB Ligand 4A5S in the binding site of DPP4 showed that these molecules had the similar binding and orientation pattern in the binding site of enzyme as that of co-crystallized ligand (6-[(3S)-3-Aminopiperidin-1-yl]5-benzyl-4-oxo-3-(quinolin-4-ylmethyl)-4,5-dihydro-3hpyrrolo[3,2-d]pyrimidine-7-carbonitrile) (Figure 3a). The docked pose of quercetin in binding site of DPP4 showed the H-bond interactions between ether ' $\mathrm{O}$ ' of chromen-4one and $\mathrm{NH}$ of Tyr631; and hydroxyl of chromen-4-one and carboxyl 'OH' of Glu205 with H-bond distance of
$3.8 \AA$, and $4.5 \AA$ respectively (Figure $3 \mathrm{~b}$ ). The docked pose of catechin in binding site of DPP4 showed the H-bond interactions between ether ' $\mathrm{O}$ ' of chromen-4-one and $\mathrm{NH}$ of Tyr631; hydroxyl of chromen-4-one and aromatic $\mathrm{OH}$ of Tyr662; and hydroxyl of chromen-4-one and carboxyl ' $\mathrm{OH}$ ' of Glu205 with H-bond distance of $4.5 \AA$, $3.1 \AA$, and $4.6 \AA$ respectively (Figure 3c). Docked pose of rutin in binding site of DPP 4 showed the H-bond interactions between phenyl hydroxyl and carbonyl of Glu205; and hydroxyl of phenyl ring and aromatic $\mathrm{OH}$ of Tyr662 with $\mathrm{H}$-bond distance of $4.5 \AA, 3.1 \AA$, and $4.6 \AA$ respectively (Figure $3 \mathrm{~d}$ ).
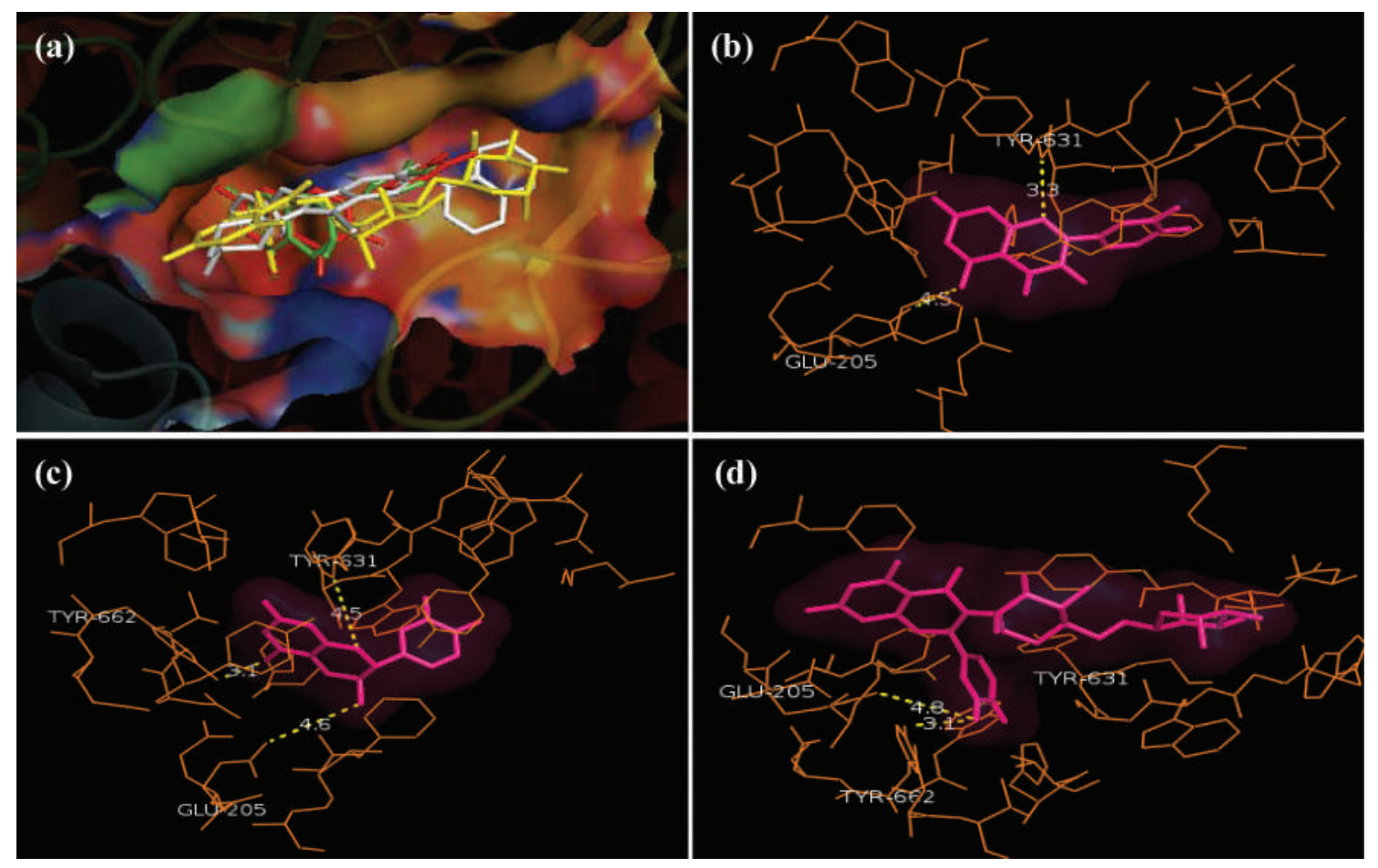

Figure 3: (a) Superimpose of quercetin (red), catechin (green) and rutin (yellow) with PDB ligand of 4A5S (white) in the binding site of DPP4; (b) Docked pose of quercetin; (c) catechin; (d) rutin in the binding site of DPP4.
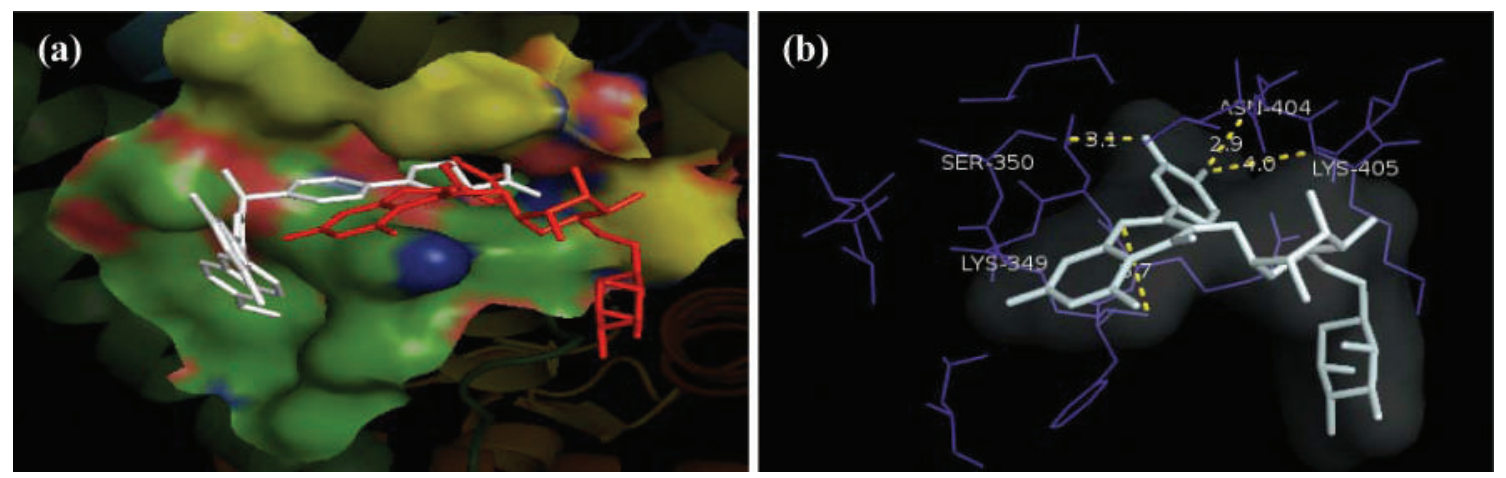

Figure 4: (a) Superimpose of rutin (red) with PDB ligand of 5EE7 (white); (b) Docked pose of rutin in the binding site of GCR. 
Overlay of the docked pose of rutin with that of PDB Ligand 5EE7 in the binding site of GCR showed that it had the similar binding and orientation pattern in the binding site of enzyme as that of co-crystallized ligand (MK0893 i.e., 3-[[4-[(1\{S\})-1-[3-[3,5-bis(chloranyl)phenyl]5-(6-methoxynaphthalen-2-yl)pyrazol-1-yl] ethyl]phenyl] carbonylamino] propanoic acid) (Figure 4a). The docked pose of rutin in binding site of GCR showed the H-bond interactions between ether ' $\mathrm{O}$ ' of chromen-4-one and $\mathrm{NH}$ of Lys349; hydroxyl of phenyl and carbonyl of Ser350; hydroxyl of phenyl and amide $\mathrm{NH}$ of Asn404; and phenyl hydroxyl and amide $\mathrm{NH}$ of Lys 405 with $\mathrm{H}$-bond distance of $3.9 \AA$, $3.1 \AA$, $2.8 \AA$, and $3.8 \AA$ respectively (Figure 4b).
Overlay of the docked pose of kaempferol with that of PDB Ligand 3IMX in the allosteric site of GK showed that it had the similar binding and orientation pattern in the allosteric binding site of GK enzyme as that of co-crystallized activator ((2R)-3-cyclopentyl-N-(5-methoxy[1,3] thiazolo[5,4-b] pyridin-2-yl)-2-\{4-[(4-methylpiperazin-1-yl)sulfonyl]phenyl\} propanamide) (Figure 5a). Kaempferol was found to bind to an allosteric pocket of GK protein, which is about $20 \AA$ remote from the glucose binding site. The docked pose of kaempferol showed the H-bond interaction between hydroxyl and carbonyl group of chromene-4-one with backbone carbonyl and amide $\mathrm{NH}$ of Arg63 on GK protein with H-bond distance of $4.9 \AA$ and $4.7 \AA ̊$ respectively (Figure 5b).
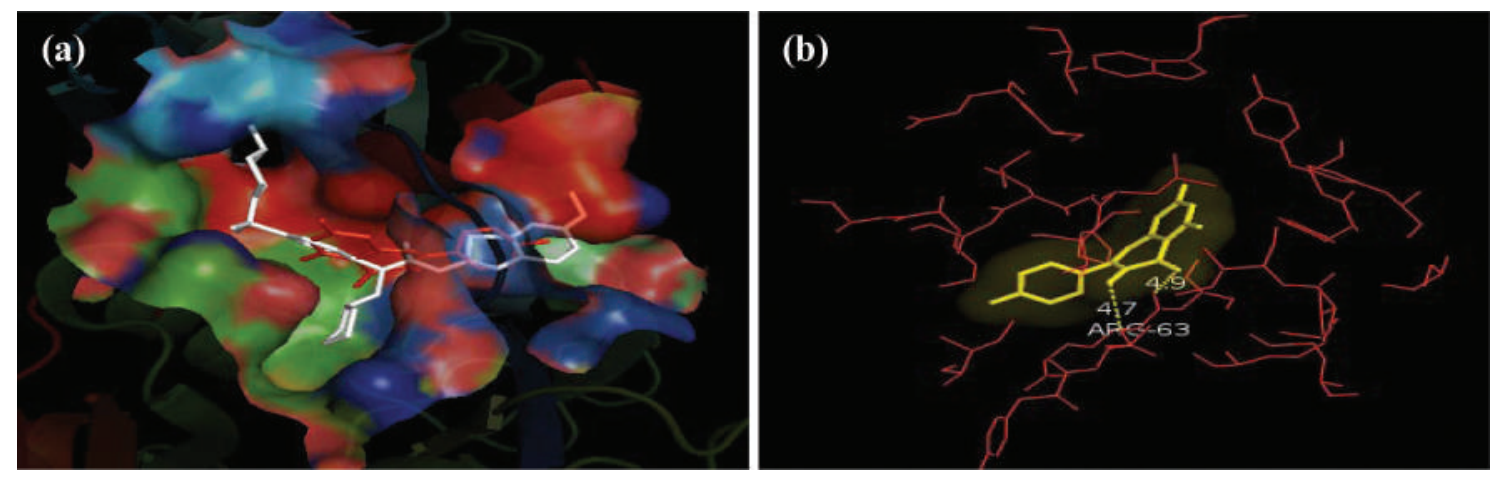

Figure 5: (a) Superimpose of kaempferol (red) with PDB ligand of 3IMX (white); (b) Docked pose of kaempferol in the allosteric site of GK.
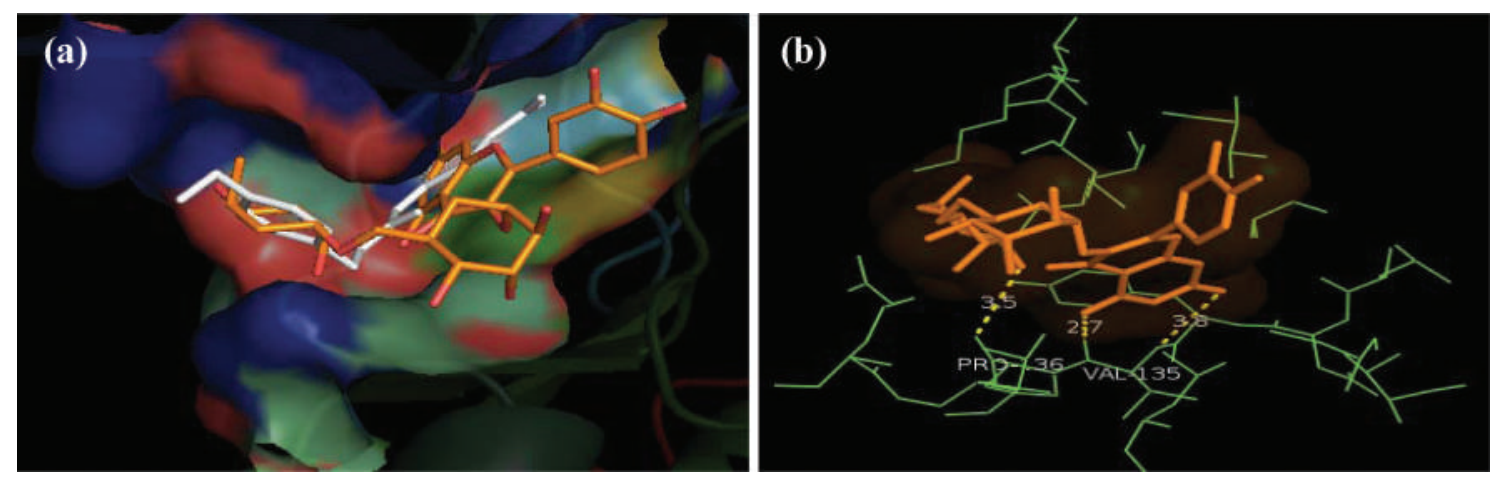

Figure 6: (a) Superimpose of rutin (red) with PDB ligand of 1Q5K (white); (b) Docked pose of rutin in the binding site of GSK3.

Overlay of the docked pose of rutin with that of PDB Ligand 1Q5K in the binding site of GSK3 showed that it had the similar binding and orientation pattern in the binding site of GSK3 enzyme as that of co-crystallized ligand (N-(4-methoxybenzyl)-N'-(5-nitro-1,3-thiazol-2-yl) urea) (Figure 6a). The docked pose of rutin in binding site of GSK3 showed the $\mathrm{H}$-bond interactions between ' $\mathrm{OH}$ ' of glucose and carbonyl of Pro136; 'OH' of oxychromen-4one and carbonyl of Val135; and carbonyl of oxychromen4-one and amide ' $\mathrm{NH}$ ' of Val135 with $\mathrm{H}$-bond distance of $2.7 \AA, 3.5 \AA$, and $3.8 \AA$ respectively (Figure $6 \mathrm{~b}$ ).

\section{Conclusion}

Molecular docking studies using AutoDock vina and AutoDock Tools was performed to explore the binding mechanism of the selected natural phenolic compounds from S. cumini with multiple targets associated with T2D. In current in silico docking study, results clearly demonstrated that amongst the compounds tested in silico, rutin showed appreciable binding with multiple targets of T2D including $\alpha$-glucosidase, dipeptidyl peptidase 4, glycogen synthase kinase 3, and glucagon receptor. Catechin was found 
to inhibit both $\alpha$-glucosidase, and dipeptidyl peptidase 4. Myricetin was found to inhibit AG and quercetin was found to inhibit DPP4. Kaempferol was found to activate allosterically GK protein. In silico study is actually an added advantage to screen the type 2 antidiabetic agents and natural phenolic compounds may serve as useful leads for the synthesis of clinically useful and safe type 2 antidiabetic agents. However, structural modifications and further studies on these natural phenolic compounds are required to develop safe and potent natural type 2 antidiabetic agents.

\section{References}

1. Afify, A. M. R., Fayed, F. A., Shalaby, E. A. and ElShemy, H. A. (2011). Syzygium cumini (pomposia) active principles exhibit potent anticancer and antioxidant activities. African Journal of Pharmacy and Pharmacology, 5(7), 948-956.

2. Avila-Pena, D., Pena, N., Quintero, S. L. and Suarez-Roca, H. (2007). Antinociceptive activity of Syzygium jambos leaves extract on rats. Journal of Ethnopharmacology, 112(2), 380-385.

https://doi.org/10.1016/j.jep.2007.03.027

3. Ayyanar, M. and Subash-Babu, P. (2012). Syzygium cumini (L.) Skeels: a review of its phytochemical constituents and traditional uses. Asian Pacific Journal of Tropical Biomedicine, 2, 240-246.

https://doi.org/10.1016/S2221-1691(12)60050-1

4. Bardy, G., Virsolvy, A., Quignard, J., Ravier, M., Bertrand, G., Dalle, S., et al. (2013). Quercetin induces insulin secretion by direct activation of L-type calcium channels in pancreatic beta cells. British Journal of Pharmacology, 169, 1102-1113.

https://doi.org/10.1111/bph.12194

5. Bastaki, S. (2005). Diabetes mellitus and its treatment. International Journal of Diabetes Metabolism, 13, 111-134.

6. Bijauliya, R. K., Alok, S., Singh, M. and Mishra, S. B. (2017). Morphology, phytochemistry and pharmacology of Syzygium cumini (Linn.) - an overview. International Journal of Pharmaceutical Sciences and Research, 8(6), 2360-2371.

7. Brito, F. A., Lima, L. A., Ramos, M. F., Nakamura, M. J., Cavalher-Machados, S. C., Henrigues, M. G., et al. (2007). Pharmacological study of anti-allergic activity of Syzygium cumini (L) Skeels. Brazillian Journal of Medical and Biological Research, 40, 105115.

https://doi.org/10.1590/S0100-879X2007000100014

8. Cade, W. T. (2008). Diabetes-related microvascular and macrovascular diseases in the physical therapy setting. Physical Therapy, 88, 1322-1335. https://doi.org/10.2522/ptj.20080008

9. Chagas, V. T., França, L. M., Malik, S. and Paes, A. M. A. (2015). Syzygium cumini (L.) skeels: a prominent source of bioactive molecules against cardiometabolic diseases. Frontiers in Pharmacology, 6, Article 259. https://doi.org/10.3389/fphar.2015.00259

10. Charaya, N., Pandita, D., Grewal, A. S. and Lather, V. (2018). Design, synthesis and biological evaluation of novel thiazol-2-yl benzamide derivatives as glucokinase activators. Computational Biology and Chemistry, 73, 221-229.

https://doi.org/10.1016/j.compbiolchem.2018.02.018

11. Chaturvedi, A., Bhawani, G., Agarwal, P. K., Goel, S., Singh, A. and Goel, R. K. (2009). Ulcer healing properties of ethanolic extract of Eugenia jambolana seed in diabetic rats : study on gastric mucosal defensive factors. Indian Journal of Physiology and Pharmacology, 53, 16-24.

12. Esmaeili, M. A., Zohari, F. and Sadeghi, H. (2009). Antioxidant and protective effects of major flavonoids from Teucriumpolium on beta-cell destruction in a model of streptozotocin-induced diabetes. Planta Medica, 75, 1418-1420.

https://doi.org/10.1055/s-0029-1185704

13. Espinoza-Fonseca, L. M. (2006). The benefits of the multi-target approach in drug design and discovery. Bioorganic \& Medicinal Chemistry, 14(4), 896-897. https://doi.org/10.1016/j.bmc.2005.09.011

14. Goyal, P. K., Verma, P., Sharma, P., Parmar, J. and Agarwal, A. (2010). Evaluation of anti-cancer and anti-oxidative potential of Syzygium cumini against benzo[a]pyrene $(\mathrm{BaP})$ induced gastric carcinogenesis in mice. Asian Pacific Journal of Cancer Prevention, 11, 753-758.

15. Grewal, A. S., Sekhon, B. S. and Lather, V. (2014). Recent updates on glucokinase activators for the treatment of type 2 diabetes mellitus. Mini Reviews in Medicinal Chemistry, 14(7), 585-602.

https://doi.org/10.2174/1389557514666140722082713

16. Grewal, A. S., Bhardwaj, S., Pandita, D., Lather, V. and Sekhon, B. S. (2016). Updates on aldose reductase inhibitors for management of diabetic complications and non-diabetic diseases. Mini Reviews in Medicinal Chemistry, 16, 120-162.

https://doi.org/10.2174/1389557515666150909143737

17. Grewal, A. S., Lather, V., Pandita, D. and Bhayana, G. (2017). Synthesis, docking and biological evaluation of phenylacetic acid and trifluoromethylphenyl substituted benzamide derivatives as potential PPAR $\delta$ agonists. Letters in Drug Design and Discovery, 14(11), 1239-1251. 
https://doi.org/10.2174/1570180814666170327164 443

18. Haraguchi, H., Kanada, M., Fukuda, A., Naruse, K., Okamura, N. and Yagi, A. (1998). An inhibitor of aldose reductase and sorbitol accumulation from Anthocepharus chinensis. Planta Medica, 64, 68-69. https://doi.org/10.1055/s-2006-957369

19. Herculano, E. D. A., Costa, C. D. F., Rodrigues, A. K. B. F., Junior, J. X. A., Santana, A. E. G., França, P. H. B. et al. (2014). Evaluation of cardiovascular effects of edible fruits of Syzygium cumini Myrtaceae (L) skeels in rats. Tropical Journal of Pharmaceutical Research, 13(11), 1853-1861.

https://doi.org/10.4314/tjpr.v13i11.12

20. International Diabetes Federation. Available at: https://www.idf.org/e-library/epidemiology-research/ diabetes-atlas/134-idf-diabetes-atlas-8th-edition.html (Accessed 10 July 2018).

21. Kamalakkannan, N. and Prince, P. S. M. (2006). Antihyperglycaemic and antioxidant effect of rutin, a polyphenolic flavonoid, in streptozotocin-induced diabetic Wistar rats. Basic and Clinical Pharmacology and Toxicology, 98, 97-103.

https://doi.org/10.1111/j.1742-7843.2006.pto_241.x

22. Kohei, K. (2010). Pathophysiology of type 2 diabetes and its treatment policy. Japan Medical Association Journal, 53, 41-46.

23. Kumar, A., Padmanabhan, N. and Krishnan, M. R. V. (2007). Central Nervous system activity of Syzygium cumini seed. Pakistan Journal of Nutrition, 6(6), 698-700.

https://doi.org/10.3923/pjn.2007.698.700

24. Kumar, R., Jayachandran, T., Deecaraman, M., Aravindan, P., Padmanabhan, N. and Krishan, M. R. V. (2008). Anti-diabetic activity of Syzygium cumini and its isolated compound against streptozotocininduced diabetic rats. Journal of Medicinal Plants Research, 2(9), 246-249.

25. Kumar, S., Saini, M., Kumar, V., Prakash, O., Arya, R, Rana, M., et al. (2012). Traditional medicinal plants curing diabetes: a promise for today and tomorrow. Asian Journal of Traditional Medicines, 7, 178-188.

26. Lagorce, D., Bouslama, L., Becot, J., Miteva, M. A. and Villoutreix, B. O. (2017). FAF-Drugs4: free ADMEtox filtering computations for chemical biology and early stages drug discovery. Bioinformatics, 33(22), 3658-3660.

https://doi.org/10.1093/bioinformatics/btx491

27. Liu, I.-M., Tzeng, T.-F., Liou, S.-S. and Lan, T.-W. (2007). Myricetin, a naturally occurring flavonol, ameliorates insulin resistance induced by a highfructose diet in rats. Life Sciences, 81, 1479-1488. https://doi.org/10.1016/j.lfs.2007.08.045

28. Mahapatra, P. K., Chakraborty, D. and Chaudhari, A. K. N. (1986). Anti-inflammatory and antipyretic activities of Syzygium cumini. Planta Medica, 6, 540. https://doi.org/10.1055/s-2007-969339

29. Miteva, M. A., Violas, S., Montes, M., Gomez, D., Tuffery, P. and Villoutreix, B. O. (2006). FAF-Drugs: free ADME/tox filtering of compound collections. Nucleic Acids Research, 34, W738-W744. https://doi.org/10.1093/nar/gkl065

30. Miteva, M. A., Guyon, F. and Tufféry, P. (2010). Frog2: Efficient 3D conformation ensemble generator for small compounds. Nucleic Acids Research, 38, W622-627.

https://doi.org/10.1093/nar/gkq325

31. Morris, G. M., Huey, R., Lindstrom, W., Sanner, M. F., Belew, R. K., Goodsell, D. S., et al. (2009). Autodock4 and AutoDockTools4: automated docking with selective receptor flexiblity. Journal of Computational Chemistry, 16, 2785-2791.

https://doi.org/10.1002/jcc.21256

32. Muruganandan, S., Srinivasan, K., Chandra, S., Tandan, S. K., Lal, J. and Raviprakash, V. (2001). Anti-inflammatory activity of Syzygium cumini bark. Fitoterapia, 72(4), 369-375.

https://doi.org/10.1016/S0367-326X(00)00325-7

33. Nair, L. K., Begum, M. and Geetha, S. (2013). In vitro-antioxidant activity of the seed and leaf extracts of Syzygium cumini. IOSR Journal of Environmental Science, Toxicology and Food Technology, 7(1), 54-62. https://doi.org/10.9790/2402-0715462

34. Namba, T., Tsunezuka, M., Dissanayake, D. M. R. B., Upali, P., Keiko, S., Nobuko, K., el al. (1985). Studies on dental caries prevention by traditional medicines part VII, screening of Ayurvedic medicines for antiplaque action. Japanese Journal of Pharmacognosy, 39(2), 146-153.

35. Ohnishi, M., Matuo, T., Tsuno, T., Hosoda, A., Nomura, E., Taniguchi, H., et al. (2004). Antioxidant activity and hypoglycemic effect of ferulic acid in STZinduced diabetic mice and KK-Ay mice. Biofactors, 21(1-4), 315-319. https://doi.org/10.1002/biof.552210161

36. Olokoba, A. B., Obateru, O. A. and Olokoba, L. B. (2012). Type 2 diabetes mellitus: a review of current trends. Oman Medical Journal, 27, 269-273. https://doi.org/10.5001/omj.2012.68

37. Osadebe, P. O., Odoh E. U. and Uzor, P. F. (2014). Natural products as potential sources of antidiabetic 
drugs. British Journal of Pharmaceutical Research, 4(17), 2075-2095.

https://doi.org/10.9734/BJPR/2014/8382

38. Patil, R., Patil, R., Ahirwar, B. and Ahirwar, D. (2011). Current status of Indian medicinal plants with antidiabetic potential: a review. Asian Pacific Journal of Tropical Biomedicine, 1(2), S291-S298. https://doi.org/10.1016/S2221-1691(11)60175-5

39. Prateek, A., Meena, R. K. and Yadav, B. (2015). Antimicrobial activity of Syzygium cumini. Indian Journal of Applied Research, 5(9), 63-66.

40. Rajasekaran, M., Bapana, J. S., Lakshmanan, A. G., Nair, R., Veliath, A. J. and Panchanadam, M. (1998). Antifertility effect in male rats of oleanolic acid, a triterpene from Eugenia jambolana flowers. Journal of Ethnopharmacology, 24, 115-121. https://doi.org/10.1016/0378-8741(88)90142-0

41. Ramsay, R. R., Popovic-Nikolic, M. R., Nikolic, K., Uliassi, E. and Bolognesi, M. L. (2018). A perspective on multi-target drug discovery and design for complex diseases. Clinical and Translational Medicine, 7(1), 3. https://doi.org/10.1186/s40169-017-0181-2

42. Ramya, S., Neethirajan, K. and Jayakumararaj, R. (2012). Profile of bioactive compounds in Syzygium cumini-a review. Journal of Pharmacy Research, 5, 4548-4553.

43. Rizvi, S. I. and Mishra, N. (2013). Traditional Indian medicines used for the management of diabetes mellitus. Journal of Diabetes Research, 2013, Article ID 712092. https://doi.org/10.1155/2013/712092

44. Scotti, L., Mendonca, F. J. Jr., Ishiki, H. M., Ribeiro, F. F., Singla, R. K., Barbosa Filho, J. M., et al. (2017). Docking Studies for Multi-Target Drugs. Current Drug Targets, 18(5), 592-604. https://doi.org/10.2174/1389450116666150825111818

45. Shamkuwar, Prashant, B., Pawar, D. P. and Chauhan, S. S. (2012). Antidiarrhoeal activity of seeds of Syzygium cumini L. Journal of Pharmacy Research, 5(12), 5537.

46. Sharma, B., Viswanath, G., Salunke, R. and Roy, P. (2008). Effects of flavonoid-rich extract from seeds of Eugenia jambolana (L.) on carbohydrate and lipid metabolism in diabetic mice. Food Chemistry, 110, 697-705. https://doi.org/10.1016/j.foodchem.2008.02.068

47. Sood, R., Swarup, D., Bhatia, D., Kulkarni, D. D., Dey, S., Saini, M., et al. (2012). Antiviral activity of crude extracts of Eugenia jambolana Lam. against highly pathogenic avian influenza $(\mathrm{H} 5 \mathrm{~N} 1)$ virus. Indian Journal of Experimental Biology, 50, 179-218.

48. Srivastava, S. and Chandra, D. (2013). Pharmacological potentials of Syzygium cumini: a review. Journal of the Science of Food and Agriculture, 93, 2084-2093.

https://doi.org/10.1002/jsfa.6111

49. Swami, S. B., Thakor, N. S., Patil, M. M. and Haldankar, P. M. (2012). Jamum (Syzygium cumini (L.)): a review of its food and medicinal uses. Food and Nutrition Sciences, 3(8), 1100-1117. https://doi.org/10.4236/fns.2012.38146

50. Tripathi, A. K. and Kohli, S. (2014). Pharmacognostical standardization and antidiabetic activity of Syzygium cumini (Linn.) barks (Myrtaceae) on streptozotocininduced diabetic rats. Journal of Complementary and Integrative Medicine, 11(2), 71-81.

https://doi.org/10.1515/jcim-2014-0011

51. Trott, O. and Olson, A. J. (2010). AutoDock Vina: improving the speed and accuracy of docking with a new scoring function, efficient optimization and multithreading. Journal of Computational Chemistry, 31, 455-461.

52. Veigas, J. M., Narayan, M. S., Laxman, P. M. and Neelwarne, B. (2007). Chemical nature stability and bioefficacies of anthocyanins from fruit peel of Syzygium cumini Skeels. Food Chemistry, 105, 619-627. https://doi.org/10.1016/j.foodchem.2007.04.022

53. Veigas, J. M., Shrivasthava, R. and Neelwarne, B. (2008). Efficient amelioration of carbon tetrachloride induced toxicity in isolated rat hepatocytes by Syzygium cumini Skeels extract. Toxicology In vitro, 22, 1440-1446. https://doi.org/10.1016/j.tiv.2008.04.015

54. Wein, S., Behm, N., Petersen, R. K., Kristiansen, K. and Wolffram, S. (2010). Quercetin enhances adiponect in secretion by a PPAR-gamma independent mechanism. European Journal of Pharmaceutical Sciences, 41, 16-22. https://doi.org/10.1016/j.ejps.2010.05.004 